\title{
Grupo de Educação para a Morte: uma Estratégia Complementar à Formação Acadêmica do Profissional de Saúde
}

\author{
Érika Arantes Oliveira-Cardoso \\ Universidade de São Paulo, SP, Brasil.
}

\author{
Manoel Antônio dos Santos \\ Universidade de São Paulo, SP, Brasil.
}

\begin{abstract}
Resumo: Os cursos de Educação para a Morte têm sido propostos como uma tentativa de preencher uma lacuna importante da formação acadêmica na área da saúde, trazendo à tona temas que, frequentemente, são negligenciados no ensino, como o processo de morrer, atitudes frente à morte, cuidados paliativos, luto do profissional, dentre outros. Esses cursos necessitam ter objetivos claramente definidos, configurando uma proposta pedagógica que busca introduzir uma postura humanista e humanizada em cursos fortemente tecnicistas. O objetivo deste estudo é descrever uma experiência de implementação do Grupo de Educação para a Morte e conhecer a percepção dos participantes sobre essa experiência. Participaram do estudo oito alunas do último ano de um curso da área de saúde de uma universidade pública, com idades entre 22 e 24 anos. Foi aplicado um questionário autopreenchido, em dois momentos: pré e pós-intervenção. As respostas às questões abertas foram submetidas à análise de conteúdo temática. Constatou-se a importância do grupo como instrumento de aquisição de conhecimentos sobre o manejo de situações de terminalidade, espaço de ressignificação da morte e do morrer, reflexão sobre atitudes, condutas e papel profissional, e mudanças nos sentimentos despertados pelo cuidado de pacientes em estado crítico de saúde.
\end{abstract}

Palavras-chave: Grupos, Ensino, Atitude Frente à Morte, Formação dos Profissionais de Saúde, Luto.

\section{Death Education Group: a Strategy to Complement Undergraduate Education of Health Professionals}

\begin{abstract}
Death Education courses have been proposed as an attempt to fill an important gap in academic health education, bringing up topics that are often neglected in teaching, such as the dying process, attitudes towards death, palliative care, professional mourning, among others. Clearly defined objectives are needed, constituting a pedagogical proposal that intends to introduce a humanistic and humanized posture into highly technical courses. This study aimed to describe the implementation of the Death Education Group and to understand how the participants perceive this experience. Eight last-year students, affiliated with a health program at a public university, between 22 and 24 years of age, participated. A self-completion questionnaire was applied at two times: pre and post-intervention. The answers to the open questions were subjected to thematic content analysis. The Group was important as a tool to gain knowledge on how to manage terminality situations, and as a space to reframe death and dying issues and to reflect about attitudes, behaviors, professional roles, and changes in the feelings aroused by the care for patients in critical health conditions.
\end{abstract}

Keywords: Groups, Teaching, Attitude to Death, Health Professionals Education, Grief. 


\title{
Grupo de Educación para la Muerte: una Estrategia Complementaria a la Formación de Pregrado del Profesional de la Salud
}

\begin{abstract}
Resumen: Los cursos de Educación para la Muerte han sido propuestos como una iniciativa para llenar una laguna importante de la formación académica en la salud, tratando temas que a menudo son descuidados en la educación, tales como el proceso de morir, actitudes hacia la muerte, cuidados paliativos, luto del profesional, entre otros. Estos cursos deben tener objetivos claramente definidos, configurando una propuesta pedagógica que busque introducir una postura humanista y humanizada en cursos que son mayormente técnicos. La finalidad de este estudio es describir la implementación del Grupo de Educación para la Muerte y conocer la percepción de los participantes sobre esa experiencia. Participaron ocho alumnas del último año de un curso del área de la salud de una universidad pública, con edades entre 22 y 24 años. Fue aplicado un cuestionario de auto-aplicación, en dos momentos: pre y post-intervención. Las respuestas a las preguntas abiertas fueron sometidas al análisis de contenido temático. Se constató la importancia del Grupo como: instrumento de adquisición de conocimiento sobre el manejo de situaciones de terminalidad; y como espacio de resignificación de la muerte y del morir, y de reflexión sobre actitudes, conductas y papel profesional, y sobre cambios en los sentimientos despertados por el cuidado de pacientes en estado crítico de salud.
\end{abstract}

Palabras clave: Grupos, Educación, Actitud Frente a la Muerte, Formación de los Profesionales de la Salud, Luto.

Educação para a Morte, no contexto hospitalar, é uma filosofia de trabalho com profissionais de saúde em questões relacionadas à morte e ao morrer. Essa modalidade de intervenção nasce de uma necessidade desencadeada pela dificuldade de enfrentamento de situações de agravamento e perdas de pacientes por membros da equipe multiprofissional (Quintana, Kegler, Santos, \& Lima, 2006). Trata-se de um trabalho complexo, inserido em um cenário sociocultural de negação da terminalidade, e que exige lidar com questões pessoais e delicadas relacionados à finitude humana (Junqueira, \& Kovács, 2008).

Informada pelo modelo biomédico, a formação dos profissionais de saúde, na maioria dos casos, ainda prioriza a busca do curar em detrimento do cuidar. Nesse contexto, a morte é significada como evidência de fracasso terapêutico, e não como uma parte inevitável e inseparável da condição humana (Pessini, \& Barchifontane, 2002). Essa crença é reforçada pelo avanço da tecnologia médica, que na atualidade possibilita o prolongamento artificial da vida - e até mesmo a sustentação da piora progressiva e do morrer do paciente antes da cessação dos sinais vitais - como parte da rotina do trabalho, o que pode produzir sofrimento e desmotivação nos profissionais de saúde (Kovács, 2005). Segundo Santos e Bueno (2011), os profissionais que lidam com a presença da morte no seu dia a dia se queixam de que o cotidiano assistencial desperta sentimentos de frustração, medo, angústia, desmotivação e insegurança.

No âmbito das políticas públicas, uma das propostas mais interessantes para se tentar superar $o$ sentimento de impotência que muitas vezes atinge os trabalhadores da saúde, que estão em contato com os desafios cotidianos de sua prática profissional, é o denominado HumanizaSUS (Brasil, 2006). Entre outros objetivos, essa estratégia busca ultrapassar os processos de trabalho fragmentados e verticalizados que imperam no âmbito hospitalar. A fragmentação da produção do cuidado, muitas vezes, leva ao isolamento do profissional e à necessidade de engendrar, individualmente, respostas para as questões que emergem no dia a dia de seu trabalho, podendo gerar intenso desgaste, cansaço e sofrimento emocional nos profissionais. Considerando a necessidade de reduzir essa vulnerabilidade, a proposta do HumanizaSUS é criar, no contexto hospitalar, espaços de produção comum de conhecimento, sem perder a noção da especificidade de cada contribuição para assegurar a integralidade do cuidado. 
O intuito é de, cada vez mais, introduzir práticas humanizadas no contexto do hospital. Essas práticas de saúde seriam responsáveis pela reintrodução do fator humano, priorizando o ser que está doente e não sua patologia (Cesnik et al., 2013; Menezes, Passareli, Drude, Santos, \& Valle, 2007; Pregnolatto, Agostinho, Dias, \& Baptista, 2003). Na concepção dos centros de atendimento mais humanizados, é crucial construir estratégias que contribuam para favorecer a elaboração e aceitação da situação de terminalidade, em especial por parte da equipe multiprofissional, quando essa realidade se impõe como um fato irrevogável. Por aceitação entende-se respeitar o momento delicado do final de vida, oferecendo possibilidades realmente efetivas de ajuda em vez de soluções ilusórias, as quais muitas vezes são implementadas em uma tentativa fútil e vã de prolongar a existência mediante a adoção de medidas heroicas (Castro, 2001).

Uma dificuldade para implementação desse modelo de atendimento é a formação acadêmica recebida pelos profissionais da saúde, que frequentemente prioriza o tecnicismo e, por isso, acaba privilegiando uma postura distanciada e insensível em relação ao outro (Junqueira, \& Kovács, 2008). O perigo da desumanização das práticas em saúde torna emergencial a oferta de estratégias educativas efetivas de como lidar com a morte e com o processo de morrer, sem ignorar seus efeitos potencialmente desestabilizadores sobre os profissionais da saúde (Santos, \& Bueno, 2011).

Pesquisas comprovam a escassez, ou até mesmo a inexistência de estudos sobre as questões da morte e do morrer no curso de graduação das profissões da saúde, o que só reforça a impressão de que esse assunto ainda é compreendido como um tabu pelos acadêmicos de diferentes áreas (Bernieri, \& Hirdes, 2007; Junqueira, \& Kovács, 2008; Marta, Marta, \& Job, 2009; Santos, \& Bueno, 2011; Santos, \& Hormanez, 2013; Vieira, Ford, Santos, Junqueira, \& Giami, 2013).

De acordo com Azeredo, Rocha e Carvalho (2011), é fato que a morte e o morrer são temas explorados no ensino da graduação, porém muitas vezes a abordagem é exclusivamente técnica, restringindo-se ao ensino de procedimentos e técnicas assépticas, uso de medicamentos e condutas profissionais a serem tomadas no momento da morte. É reduzido o espaço destinado ao questionamento dos sentimentos despertados no profissional de saúde pelo cuidado e eventual perda de paciente gravemente enfermo e/ou pelo contato com o drama dos familiares enlutados (Arruda-Colli \& Santos,
2015; Arruda-Colli, Perina, \& Santos, 2015; Arruda-Colli, Perina, Mendonça, \& Santos, 2015; Pereira \& Santos, 2012). Isso tem contribuído para alimentar uma cultura de negação da dor emocional dos profissionais de saúde, especialmente daqueles que estão mais expostos a perdas recorrentes, como os que atuam na área da oncologia (Santos, 2003).

Experiências internacionais, que datam de várias décadas de prática, confirmam que a dificuldade em lidar com as questões da morte e do morrer, presentes em praticamente todos os contextos e mais aguçadas em alguns, pode ser enfrentada por meio do conhecimento, e consequentemente, do melhor preparo profissional para se lidar com a terminalidade (Brabant, \& Kalish, 2008). Estudo reforça a necessidade de um trabalho cuidadoso, que leve em consideração, por um lado, a necessidade saudável de um determinado nível de negação da morte, e por outro, a visão de que tal negação, em geral, é exacerbada no contexto da saúde, sendo a compreensão da complexidade do morrer muito pouco explorada (Tucker, 2009).

Ao considerar esse panorama, os cursos de Educação para a Morte têm sido propostos como uma tentativa de preencher uma lacuna importante da formação acadêmica dos profissionais de saúde, trazendo à tona temas que, habitualmente, são negligenciados no decorrer dos cursos de graduação, tais como: o processo de morrer, atitudes frente à morte, cuidados paliativos, luto do profissional, luto antecipatório, processo de enlutamento, dentre outros (Kovács, 2009). Tais cursos necessitam ter objetivos claramente definidos e bem delineados, configurando uma proposta pedagógica e não psicoterapêutica, que busque introduzir a já mencionada postura mais humanista em cursos que, tradicionalmente, se caracterizam por uma abordagem fortemente tecnicista (Kovács, 2003).

A configuração ideal do modelo pedagógico, segundo Junqueira e Kovács (2008), é a que contempla a união entre teoria e prática, em uma práxis que abre espaço para a discussão, o debate de ideias, o pensamento crítico e a reflexão a respeito das experiências dos participantes. Orienta-se que os cursos sejam de curta duração e focalizem conhecimentos e reflexões sobre a terminalidade, buscando favorecer o contato do educando com os seus próprios sentimentos. Para tanto, se faz necessária a instauração de um clima de segurança e confiança, que possibilite ao participante compartilhar com o grupo suas experiências e reflexões, sem receios de não ser compreendido 
ou de receber críticas e julgamentos ao compartilhar suas vivências (Junqueira, \& Kovács, 2008).

É importante que se inclua, no processo de ensino-aprendizado, o exame dos componentes emocionais que o contato com o paciente e seus familiares despertam nos estudantes e profissionais em formação, bem como das representações sociais que circulam no espaço coletivo sobre o adoecimento, o sofrimento e a terminalidade. Acredita-se que promover ambientes de discussão dessas vivências pode minimizar as consequências das dificuldades em lidar todo dia com essas questões tão mobilizadoras de afeto (Quintana et al., 2008), uma vez que o contato com a dor do outro pode aumentar a suscetibilidade à própria dor do profissional de saúde, em especial daqueles menos experientes (Santos, 2003).

Um ponto importante é a escolha do profissional que conduzirá o grupo de Educação para a Morte, uma vez que é comum, entre os próprios docentes do curso, experimentar sentimentos de desamparo, insegurança, temor e a percepção do próprio despreparo para conduzir esse trabalho, já que necessitam pensar em "como ensinar aquilo que nunca foi aprendido" (Santos, \& Bueno, 2011, p. 275). Preconiza-se que seja um profissional que tenha experiência com questões sobre a morte e o morrer, e que consiga conduzir, com relativa serenidade, discussões e reflexões sobre esses temas complexos e desafiadores.

Considerando os aspectos levantados e a escassez de conhecimento sobre grupos educativos que problematizem a morte e o morrer em nossa realidade, este estudo teve por objetivo descrever uma experiência de implementação de um Grupo de Educação para a Morte e analisar as percepções dos alunos que participaram dessa experiência a respeito de suas expectativas iniciais, incluindo uma apreciação sobre a experiência e satisfação com o conhecimento adquirido.

\section{Método}

\section{Cenário}

O Grupo de Educação para Morte foi implementado em um hospital universitário do interior do Estado de São Paulo, e é parte de um trabalho mais amplo que envolve introduzir intervenções que problematizem os desafios vivenciados no contexto da morte e do morrer por profissionais da saúde, pacientes e cuidadores familiares. A parceria com a institui- ção hospitalar data de vários anos, sendo que o Grupo objeto deste estudo foi a quarta experiência desenvolvida em parcerias estabelecidas com diferentes setores do referido hospital. Não se trata de um trabalho regular, desenvolvido sistematicamente, pois ocorre por demanda, na medida em que há solicitação por parte da instituição.

A motivação para o pedido de intervenção psicológica está relacionada às dificuldades identificadas nos alunos de graduação no momento em que iniciavam suas atividades de estágio em unidades clínicas reconhecidas como de alto estresse e/ou elevada mortalidade. Na percepção dos profissionais vinculados à instituição hospitalar, essas dificuldades geravam intenso sofrimento nos alunos, para o qual não se vislumbravam possibilidades de resolução no cotidiano institucional.

O Grupo era fechado, de tempo limitado, coordenado por uma psicóloga especialista em Psicologia Hospitalar, com ampla experiência profissional de manejo de pacientes em situação de terminalidade, e que já havia coordenado essa modalidade de curso voltado para graduandos e pós-graduandos, de diferentes áreas da saúde, que iniciavam suas atividades de assistência aos doentes com quadros clínicos graves no contexto hospitalar.

\section{Participantes}

O Grupo de Educação para a Morte foi implementado junto a alunos de um curso de graduação, que no transcurso de um estágio profissionalizante apresentavam queixas de dificuldades no contato com pacientes graves, especialmente nos momentos de piora e agravamento do quadro clínico (Tabela 1). A solicitação do Grupo se deu por iniciativa da supervisora responsável pelas atividades do estágio, sensível às dificuldades detectadas na formação acadêmica em diferentes cenários da instituição hospitalar. Essas dificuldades tinham, em comum, a alta vulnerabilidade dos graduandos ao estresse e esgotamento profissional.

Participaram dos encontros oito alunas do último ano do curso de nutrição de uma universidade pública do interior paulista. Todas as participantes estavam desenvolvendo atividades relacionadas a um estágio curricular oferecido no hospital geral, distribuídas em diferentes unidades de alta complexidade e mortalidade, tais como: Hematologia, Oncologia, Unidade de Transplante de Medula Óssea e Oncopediatria. 
Tabela 1

Caracterização das participantes do Grupo de Educação para a Morte $(n=8)$.

\begin{tabular}{lccc}
\hline Participantes & Sexo & Idade & $\begin{array}{c}\text { Local do estágio } \\
\text { curricular }\end{array}$ \\
\hline 1 & F & 22 & Hematologia \\
2 & F & 23 & Oncologia \\
3 & F & 22 & $\begin{array}{c}\text { Transplante de } \\
\text { medula óssea }\end{array}$ \\
4 & F & 24 & Pediatria \\
5 & F & 23 & Oncopediatria \\
6 & & & Hematologia \\
7 & F & 24 & Oncologia \\
\hline 8 & F & 24 & \\
\hline
\end{tabular}

\section{Instrumentos}

Questionário

Foi elaborado um questionário, dividido em duas partes, sendo a primeira aplicada no momento da pré-intervenção e a outra, na etapa pós-intervenção. Esse instrumento de autopreenchimento continha questões abertas e fechadas, que abordavam os seguintes tópicos:

- Como cheguei para realizar esse curso (resposta aberta):

O propósito dessa questão era conhecer quais as expectativas que as alunas "levavam na bagagem”, como percebiam sua necessidade de participar do grupo, o que esperavam obter nos encontros e quais os eventuais receios ou fantasias que tinham em relação a essa participação.

- Meu nível de conhecimento prévio (pontuar em uma escala de 0-10):

Trata-se de uma autoavaliação, na qual os alunos pontuavam em uma escala de 0 a 10 - sendo zero equivalente a nenhum conhecimento e 10 a conhecimento suficiente - o quanto acreditavam ter de informações sobre a morte e o morrer que os auxiliavam na prática clínica.
- Como estou saindo do curso (resposta aberta):

O propósito dessa questão era conhecer o quanto os alunos acreditavam ter atingido o objetivo proposto pelo curso, que tipo de conhecimento foi adquirido, o que facilitou e o que dificultou a aprendizagem.

- Meu conhecimento atual (pontuar em uma escala de 0-10):

Seguiu-se o mesmo sistema de autoavaliação utilizado anteriormente, mensurando-se pela segunda vez o mesmo quesito: o quanto os alunos se sentem preparados, em termos de domínio do conhecimento percebido como necessário nesse momento para lidar com as questões da terminalidade, que perpassam a prática no contexto hospitalar.

O instrumento foi elaborado pelos pesquisadores com base na literatura da área, levando-se em consideração aspectos considerados como relevantes, tais como: as dificuldades e o sofrimento emocional a que o aluno está exposto ao lidar com as questões da terminalidade do paciente (Kovács, 2003), a percepção de se ter pouco conhecimento consolidado sobre o processo de morte e morrer (Bernieri, \& Hirdes, 2007) e a possibilidade de mudança em termos afetivos e de aquisição de conhecimento por meio do trabalho com um grupo de educação para morte (Marta et al., 2015; Sullivan, Lakoma, Billings, Peters, \& Block, 2005; Ury, Arnold, \& Tulsky, 2002).

$\mathrm{O}$ instrumento foi previamente submetido à apreciação de um comitê constituído por três especialistas, com o objetivo de verificar a pertinência e adequação das questões. Ajustes sugeridos pelo comitê foram incorporados, com o objetivo de aprimorar o instrumento antes de sua aplicação com os participantes.

Diário de campo

O diário de campo consistiu de registros das observações realizadas pelos pesquisadores em todos os encontros realizados. Também foram registrados os fatos mais significativos percebidos durante a aplicação e reaplicação do questionário.

\section{Procedimento}

A coleta de dados foi iniciada após aprovação do protocolo de pesquisa pelo Comitê de Ética em Pesquisa da instituição a que os pesquisadores estão vinculados, adotando-se os procedimentos éticos de respeito aos participantes, de acordo com a Resolução no 466 sobre Pesquisa Envolvendo Seres Humanos (Brasil, 2012). 
As avaliações ocorreram no primeiro encontro, antes mesmo de ser explicada a proposta e estabelecido o contrato de trabalho, e novamente no dia do encerramento do Grupo, pouco antes de ser realizada uma discussão grupal sobre o processo vivenciado pelo grupo. Os questionários foram aplicados em situação coletiva e demandaram, em média, 20 minutos para o preenchimento.

\section{Análise dos dados}

Os conteúdos produzidos pelas participantes nas respostas às questões abertas foram digitados e analisados qualitativamente, por meio da análise de conteúdo temática (Triviños, 1992). Para tanto, foram seguidos os seguintes passos metodológicos:

- pré-análise: essa etapa compreendeu a organização do material e a sistematização das principais ideias contidas nas respostas aos questionários e nos diários de campo;

- descrição analítica: nessa fase foi realizada a categorização dos relatos;

- interpretação referencial: abrangeu o tratamento e a interpretação dos dados, com base no marco teórico que norteou a pesquisa, compreendendo os estudos de tanatologia e Psicologia da Morte (Kovács, 2003, 2005, 2009). Posteriormente, foram selecionados alguns excertos de falas para ilustrar as categorias de análise elaboradas.

Da análise de conteúdo temática emergiram quatro categorias: $\mathrm{O}$ encontro com o esperado, Instrumentalizando-se teoricamente, Instrumentalizando-se vivencialmente, $\mathrm{O}$ encontro com o inesperado e Avaliando o processo de aprendizagem.

\section{Resultados e Discussão}

\section{Implementação dos encontros}

De acordo com Kovács (2005), os cursos que visam a preparar os estudantes ou profissionais da saúde para lidarem com os reveses das situações de morte e do morrer necessitam ter objetivos bem delimitados, uma clara ênfase em uma proposta pedagógica e cunho não psicoterapêutico. Um dos objetivos, segundo a autora, é introduzir uma postura mais humanista como pressuposto dos cuidados em saúde. Um ensino que aliasse teoria e prática, com espaços para discussão de vivências e reflexões sobre situações críticas da prática clínica, foi o modelo ideal sugerido pelos alunos, que procuravam compreender melhor as questões relacionadas à morte e ao processo de morrer (Junqueira, \& Kovács, 2008).

Essas considerações foram ponderadas quando os pesquisadores receberam o convite, feito pela supervisora responsável pelos estágios desenvolvidos pelas alunas, para elaborarem uma proposta de intervenção educativa que pudesse auxiliar no enfrentamento das dificuldades observadas - e que as alunas confirmariam, posteriormente. No pedido formulado havia a clara indicação de que as potenciais participantes dessa intervenção estavam vivenciando dificuldades em lidar com as questões inerentes ao manejo de situações relacionadas à morte e ao morrer, quando inseridas em práticas clínicas que envolviam pacientes em situação de terminalidade (em especial naquelas que abrangiam atendimento de crianças), no contexto de um hospital-escola público.

Em resposta à solicitação, foi implementado o Grupo de Educação para Morte, com caráter informativo e crítico-reflexivo. O objetivo do grupo era oferecer às participantes alguns elementos teóricos e vivenciais básicos sobre a morte e o morrer, possibilitando um olhar crítico e ampliado para a prática clínica, visando à conquista de um cuidar mais humanizado por parte dos profissionais em formação. Além disso, esperava-se que o espaço pudesse servir para acolhimento e reflexão a respeito de situações angustiantes vivenciadas pelas alunas.

Os encontros aconteceram semanalmente, ao longo de um semestre letivo, totalizando seis reuniões, com duração de duas horas cada. Esse número de encontros e sua duração foram determinados após o primeiro encontro, momento no qual foram conhecidas as demandas e delineada com o grupo a duração da intervenção. Um dos encontros foi reservado à discussão de questões teóricas e os demais contemplaram vivências e o compartilhamento de reflexões das participantes. De um modo sucinto, os encontros compreenderam as seguintes atividades:

\section{$O$ encontro com o esperado}

O primeiro encontro foi reservado para apresentação das participantes e para levantamento das demandas. Elas se apresentaram, identificaram as clínicas nas quais realizavam estágio e expuseram as dificuldades que enfrentavam no desempenho 
do papel profissional. Também foram levantadas as expectativas das participantes em relação ao grupo educativo. Nesse encontro foi aplicada a primeira parte do questionário. Foram ainda estabelecidos dias, horários e temas a serem abordados durante os encontros, e foram definidos os textos que deveriam ser lidos nos intervalos entre as reuniões e que pautariam cada encontro.

As participantes relataram que vieram em busca de uma oportunidade para falarem do sofrimento desencadeado pelo contato com as situações de atendimento de pacientes em situação crítica, em especial as que envolviam uma piora progressiva do estado clínico e sua evolução a óbito. Mencionaram a necessidade de contar com um espaço, no âmbito da formação acadêmica, para refletirem sobre os limites e potencialidades de suas ações no ambiente hospitalar, em busca de intervenções que fossem além dos aspectos meramente técnicos.

Apareceram como fatores motivadores para a busca de ajuda por parte do profissional da saúde: angústia relacionada à piora e morte do paciente, medo de não saber como lidar com o sofrimento do paciente e seu familiar, insegurança em relação ao modo de se posicionar na equipe de saúde e medo de "não dar conta" do estágio, por não ter competência emocional para suportar as situações desafiadoras.

Tenho angústias sobre como lidar com a morte de um paciente, como lidar com o sofrimento do familiar, sobre como lidar com a equipe multidisciplinar e, principalmente, como lidar com o sofrimento gerado em mim (Participante 1).

Em uma pesquisa realizada com acadêmicos do curso de Enfermagem, com o propósito de investigar o preparo para lidar com as questões da morte e do morrer, os autores relataram que essa temática constitui um verdadeiro tabu entre os estudantes e que a necessidade de enfrentá-la de forma recorrente desperta sentimentos como medo, angústia, frustração, culpa e ansiedade (Bernieri, \& Hirdes, 2007). De modo geral, os estudantes se sentem despreparados para enfrentar as situações que os colocam em contato com a finitude humana.

Tais temores são, em certa medida, relacionados aos formidáveis avanços da tecnologia biomédica, que vêm possibilitando o prolongamento do tempo de sobrevida dos pacientes, independentemente da qualidade de vida associada a esse acréscimo de tempo. A crença na supremacia tecnológica fez com que a morte fosse progressivamente deslocada para os hospitais, que, por outro lado, se configuram ainda como instituições empenhadas no processo de cura (Azeredo et al., 2011), comprometidas com a ênfase atribuída ao tratar em detrimento do cuidar. Os progressos da medicina fizeram com que o cuidado de pacientes graves e de seus cuidadores fosse se tornando cada vez mais prolongado, o que produz um aumento da carga de estresse e de sofrimento emocional do cuidador profissional (Kovács, 2005).

A insegurança é alimentada pelo fato de que o contexto hospitalar, apesar de ser o locus escolhido na era contemporânea para desempenhar a missão social de abrigar os cuidados de final de vida, também é o lugar em que a representação da morte foi banida, evitando-se nomeá-la ou estendendo os limites da vida o máximo possível, com apoio de aparatos tecnológicos cada vez mais sofisticados. A educação médica incentiva a negação da finitude (Aoki, Oliveira-Cardoso, \& Santos, 2013; Santos, \& Hormanez, 2013) e a formação acadêmica das demais categorias de profissionais de saúde acompanha essa tendência, inclusive pela total exclusão, omissão ou negligência em relação à abordagem dessa temática durante o curso de graduação.

Com efeito, em alguns relatos iniciais apareceu a curiosidade, e até mesmo o ceticismo, de que os encontros grupais pudessem efetivamente auxiliar no manejo das situações de ansiedade:

Estou curiosa para conhecer a visão da Psicologia, e com dúvida sobre a minha conduta (se adequada ou não), em especial nos casos em que o paciente piorava e estava mais próximo da morte (Participante 4).

Apesar de ser teoricamente esperado, tal clima de desconfiança, relacionado provavelmente ao caráter novo e desconhecido da atividade profissional, necessita ser dissipado, uma vez que, para efetividade do trabalho educativo, faz-se necessário garantir um ambiente de confiança e respeito, que possibilite um olhar para si mesmo, a percepção e confronto com seus próprios sentimentos e limites, bem como o compartilhar da experiência emocional com o grupo, sem receios de receber críticas, ataques e julgamentos (Junqueira, \& Kovács, 2008). 


\section{Instrumentalizando-se teoricamente}

No segundo encontro foi realizada a apresentação de material teórico sobre as dimensões psicológicas do adoecimento, tratamento, terminalidade e luto (Aoki et al., 2013; Cardoso, \& Santos, 2013, Kovács, 2005; Oliveira, Santos, \& Mastropietro, 2010; Santos, Ford, Santos, \& Vieira, 2014; Souza et al., 2014). Foram indicadas leituras de textos selecionados e efetuada uma explanação sobre as implicações emocionais do adoecimento e o impacto subjetivo gerado pela necessidade de tratamento hospitalar. Também foram discutidas as possibilidades de apoio emocional na terminalidade e no processo de enlutamento.

Inicialmente, cinco das alunas classificaram o conhecimento que detinham sobre educação para morte com nota cinco (ponto central da escala), uma aluna estimou seu conhecimento como equivalente a seis, uma com três e outra com dois. Em média, a pontuação obtida foi 4,5 (desvio-padrão = 1,2), indicando que as participantes julgavam ter um conhecimento mediano sobre o assunto, com tendência a insuficiente, e alegaram ter discutido muito pouco sobre o tema durante o curso da graduação.

Declararam ter tido contato prévio com a temática da morte, mas destacaram uma incoerência entre o nível de conhecimento recebido como graduandas e a "cobrança" que receberam quando desempenhavam o papel de estagiárias, conforme ilustrado na seguinte fala:

Me sentia perdida. Eu era cobrada como profissional, esperavam que eu tomasse condutas e eu ainda me sentia e me via como uma estudante que precisava de orientação e que não sabia como agir em muitas das situações (Participante 3).

A sensação de ter pouco ou nenhum preparo técnico e emocional, ou mesmo o reconhecimento de seu franco despreparo para lidar com as situações de morte, aparece também como resultados de pesquisas com graduandos de diversos cursos da área de saúde, como Enfermagem, Medicina e Psicologia. Esses cursos, apesar de envolverem muitas vezes o cuidado intenso e direto com o paciente, ainda parecem mais preocupados com o ensino de questões técnicas do que do contato e manejo dos próprios sentimentos dos futuros profissionais (Azeredo, Rocha, \& Carvalho, 2011; Bernieri, \& Hirdes, 2007; Junqueira, \& Kovács, 2008).
A participação na aula teórica, na opinião das participantes, superou as expectativas. As alunas realizaram as leituras, elaboram questões e durante a atividades conseguiram relacionar teoria e prática clínica, como fica patente na fala de uma das participantes: "Acho que precisaríamos ter aulas deste tipo na graduação. Eu iria mais tranquila para a prática se tivesse contato com este tipo de conteúdo antes" (Participante 5).

\section{Instrumentalizando-se vivencialmente}

$\mathrm{O}$ terceiro e quarto encontros foram reservados para a discussão das situações clínicas vivenciadas pelas alunas com pacientes, seus familiares e a equipe multiprofissional. Percebeu-se que muitas das reflexões foram desencadeadas pelo conteúdo anterior da aula teórica.

Nesse momento, as alunas foram encorajadas a compartilharem as situações vivenciadas na prática clínica, nas quais consideravam que não souberam como agir ou o que falar, devido à extrema mobilização emocional que sentiram.

Os sentimentos e sensações preponderantes nas participantes do presente estudo foram: angústia, medo, insegurança, revolta, confusão, solidão e raiva. Também foram mencionadas dificuldades tais como: despreparo emocional, desconhecimento e inexperiência, o que sugere que ignorar o sofrimento decorrente do atendimento de pacientes críticos pode contribuir para aumentar o grau de confusão dos alunos que se encontram em etapa de formação profissionalizante. Em geral, as falas se concentraram na dificuldade em atender pacientes que apresentavam piora clínica e no medo de não saberem como agir quando questionadas por estes, ou pelos familiares, a respeito de questões relacionadas à terminalidade. "Meu grande problema é com o paciente que está grave. Eu tenho medo de ele me perguntar, por exemplo, se ele vai morrer e eu não saber o que falar" (Participante 1).

Outro medo significativo que emergiu foi o temor de exposição da própria emoção vivenciada nas situações de atendimento, de modo que poderiam parecer frágeis aos olhos do paciente ou do familiar, e em especial da equipe multiprofissional. "Meu medo é que sou manteiga derretida, tenho pavor em pensar que posso ter uma crise de choro perto do paciente... Desse jeito, como a família e a equipe vão continuar confiando em mim?" (Participante 5).

De acordo com Kovács (2003), a confirmação da incurabilidade e a possibilidade de agravamento dos 
sintomas e piora do quadro clínico, ou mesmo a ocorrência da morte do paciente, podem configurar situações desencadeadoras de ansiedade e intenso estresse emocional nos membros da equipe multiprofissional. Isso pode acarretar reações e defesas maciças, que fazem com que o trabalho assistencial seja percebido como desmotivador e até mesmo desnecessário. De fato, as dificuldades em lidar com o agravamento da condição clínica dos pacientes e com a situação de terminalidade foram recorrentes nos relatos das participantes: "É um sentimento de injustiça, no caso de morte ou piora inesperada" (Participante 3 ).

Essas experiências eram examinadas no espaço grupal, de modo a serem melhor compreendidas e discutidas, até que possibilidades de ações pudessem ser vislumbradas, com ênfase nos aspectos da comunicação profissional-paciente. Destacou-se, nesse momento, o "peso" da responsabilidade embutida no exercício do papel de profissional em formação e a sensação de que, como alunas, eram mais "cobradas" do que propriamente orientadas por suas supervisoras. "A gente trabalha com pacientes graves... a equipe cobra da gente respostas e condutas e a gente nem é formada... Isso dá uma sensação ruim de muita cobrança" (Participante 1). "Eu estou confusa sobre como lidar com algumas questões da enfermaria. Sentia raiva em alguns momentos, despreparo e falta de apoio" (Participante 6).

Esses sentimentos negativos muitas vezes eram desencadeados pela sensação de impotência vivenciada ao entrar em contato com a inexorabilidade do processo de morrer de um paciente. Nos relatos obtidos no presente estudo, nota-se que o sentimento de desamparo das estudantes tende a se acentuar com a percepção da falta de apoio por parte dos professores, os quais, provavelmente, também se encontravam despreparados para transmitir um saber capaz de tranquilizar os alunos e aplacar suas angústias mais agudas frente à situação de finitude. A insegurança que permeia os relatos obtidos nesse contexto, segundo Junqueira e Kovács (2008), aparece aliada à falta de conhecimento e ao medo de confrontar os sentimentos que o contato com o desconhecido desperta.

\section{$O$ encontro com o inesperado}

A proposta de discussão de um filme causou certo estranhamento em um primeiro momento, por não se tratar de uma abordagem usual no curso do qual provinham, mas foi prontamente aceita por todas. O combinado foi de assistirem ao filme durante o intervalo dos encontros, de maneira que o espaço do grupo se mantivesse reservado para sua discussão.

O filme escolhido foi "Intocáveis" (Toledano, \& Narache, 2012), em função de abordar a temática do cuidador formal (ou seja, profissional), enfatizando as dores decorrentes de diversas perdas decorrentes de uma grave condição que paralisou totalmente o personagem que se encontrava sob cuidados. Essas perdas, contudo, eram entremeadas com momentos intensos de interação marcados pela descontração, humor e leveza do cuidador.

Durante a discussão no grupo foram levantados temas tais como: as características do cuidador ideal, a necessidade de incorporar o afeto no cuidado, as limitações suscitadas pelo adoecimento e a necessidade de identificar e fortalecer as potencialidades do paciente. "Fiquei pensando na ideia que a gente tem do cuidador ideal... aquele ser distanciado, técnico, frio, mas o que ajudou ali não foi esse tipo de cuidador, né?" (Participante 3).

Refletiu-se sobre como essa discussão poderia auxiliar na prática clínica de cada participante, ampliando seu repertório de estratégias e recursos internos que poderiam ser utilizados frente aos desafios encontrados.

Acho que isso vem mostrar que o afeto é muito importante, mas não o afeto da pena, da piedade... Fiquei pensando em quantas vezes olhei com pena para o meu paciente, sem pensar no que ele ainda era capaz de fazer (Participante 8).

Transformações em suas reações e condutas foram percebidas pelas participantes no decorrer do processo educativo, especialmente em relação aos atendimentos realizados a pacientes e familiares, e também no contato estabelecido com a equipe multiprofissional. Também se constatou a possibilidade de utilizar a empatia como instrumento de aproximação, com os devidos cuidados para que essa ferramenta não servisse como mecanismo favorecedor de maciça identificação com o sofrimento do paciente ou do familiar. Empatia, nesse contexto específico, está sendo compreendida como a "capacidade de entender aquilo que uma pessoa está sentindo e transmitir-lhe compreensão, mantendo ao mesmo tempo certa objetividade para poder prestar a ajuda necessária" (Fish, \& Shelly, 1986, p. 110). 
O desafio é encontrar o ponto de equilíbrio, ou seja, uma distância ótima, que é aquela posição em que não se está nem tão longe, a ponto de se perder a possibilidade de entrar em contato profundo com o outro, nem tão perto, a ponto de borrar ou diluir as fronteiras psíquicas que separam o profissional do paciente/familiar. Trata-se do conceito postulado por Bleger (2003), denominado de "dissociação instrumental", segundo o qual o profissional deve se esforçar por compreender empaticamente seu paciente, mas, ao mesmo tempo, deve saber manter um certo distanciamento que lhe possibilite ajudá-lo instrumentalmente, ou seja, de um ponto de vista técnico, sem se deixar "invadir" emocionalmente por seu sofrimento: "Consigo agora me colocar na situação do outro e saber que não é fácil; sem negar o ruim, a dor do mesmo e sabendo que falsas esperanças são maléficas ao paciente" (Participante 2).

Após a intervenção, essa graduanda parecia ser sentir mais capacitada para o cuidar, vislumbrando a necessidade de ir além da mera aplicação de conhecimentos técnicos, tendo como balizador ético o apreço pela verdade, sem alimentar "falsas esperanças" no paciente e em seus familiares. Essa percepção é extremamente valorizada na cultura atual de cuidado humanizado, pois sinaliza a assunção a uma postura equilibrada diante das situações delicadas com que os profissionais se deparam no seu cotidiano. Além de trabalhadores tecnicamente competentes, há uma urgência no cenário atual de formar cuidadores sensíveis e capazes de lidar com seus sentimentos, e que saibam instrumentalizá-los de modo "humanamente sofisticado" (Bernieri, \& Hirdes, 2007). "Não sinto mais necessidade de me esquivar do paciente quando ele demonstra outras demandas não relacionadas à nossa prática" (Participante 5).

Apesar de se colocarem de modo mais inteiro e afetivo nas relações de cuidado, as participantes demonstraram ter compreendido a necessidade de saberem manter um distanciamento seguro do seu trabalho no hospital, de modo que o restante de suas vidas pudesse ser preservado, separando o âmbito profissional da esfera particular, o que não conseguiam até então.

Estou saindo com uma bagagem de conhecimentos que me proporciona melhor estrutura para lidar com a morte e o sofrimento do paciente e do familiar, respeitando as angústias que esses causam em mim. Consigo agora separar melhor a vida pessoal da profissional (Participante 1).
Nota-se, nesse relato, a importância de aprender a discriminar o que é próprio do que é do outro. Essa diferenciação envolve o autorrespeito, ou seja, a capacidade de examinarem os próprios limites, de modo a dimensionar adequadamente o valor e a extensão que o desempenho do papel profissional deve ter na vida de cada um e, assim, encontrar um equilíbrio saudável entre vida e trabalho. Esse equilíbrio, uma vez conquistado, age de maneira protetora, permitindo que o profissional esteja habilitado para exercer suas funções de maneira mais adequada, ajustando suas expectativas com as possibilidades e limites da realidade.

\section{Avaliando o processo de aprendizagem}

O último encontro foi reservado para a avaliação e encerramento da intervenção educativa. Nesse momento, foi novamente aplicado o questionário e realizado o encerramento do Grupo de Educação para a Morte. As alunas puderam se manifestar sobre a avaliação do processo que estava em vias de ser encerrado, ressaltando pontos positivos e dificuldades vivenciadas no decorrer do percurso.

Dentre as participantes que, inicialmente, valoraram o conhecimento que já dominavam com a nota cinco, três o reclassificaram, ao término da intervenção, com a nota nove, dois com oito e um com sete pontos. Os que, inicialmente, haviam pontuado seis e dois evoluíram para nove e o participante que havia cravado a nota três evoluiu para seis (Figura 1). Em média, a pontuação final foi 8,2 (desvio-padrão = 1,1).

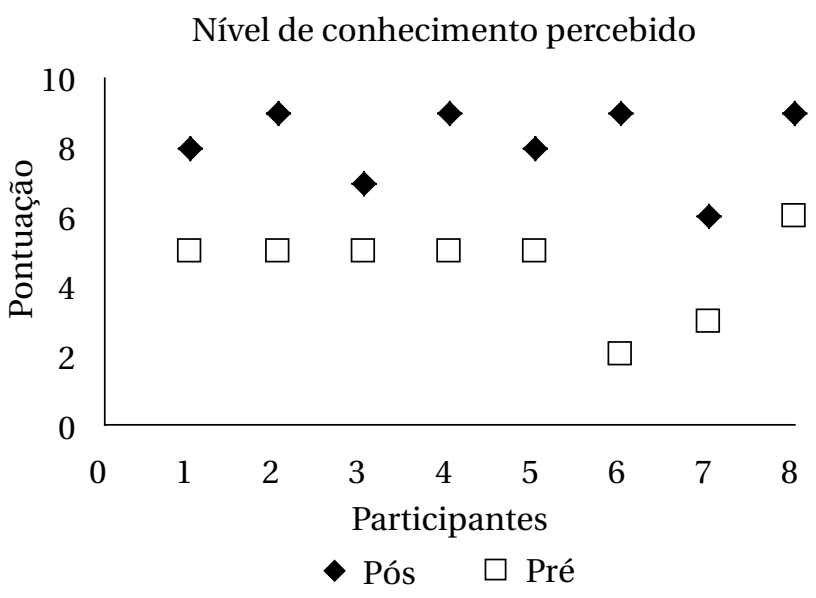

Figura 1

Autopercepção das participantes quanto ao seu nível de conhecimento nas etapas pré-intervenção e pós-intervenção. 
Observa-se que todas as participantes referiram ter aumentado o seu nível de conhecimento sobre a temática da morte e do morrer em comparação com o momento prévio ao início da intervenção, sendo o maior incremento da ordem de sete pontos e o menor, de dois pontos. Nas palavras de uma das participantes: "As expectativas foram supridas e trouxeram mais conhecimentos que o esperado, me ajudaram muito nas vivências do estágio, e também acredito que ajudarão no futuro" (Participante 8).

Em relação às técnicas utilizadas para promover o ambiente de aprendizagem e favorecer o debate dos assuntos trabalhados, os alunos destacaram como sendo de fundamental importância a discussão das situações práticas por eles vivenciadas, que geraram reflexões e mudanças na maneira de olhar para o tema. "O mais importante foi pensar além da teoria e refletirmos sobre a nossa prática profissional. Isso fez a diferença" (Participante 5).

A necessidade de aliar a teoria à prática é reconhecida na literatura como um recurso fundamental para o sucesso do trabalho com Grupos de Educação para a Morte (Junqueira, \& Kovács, 2008). Trata-se, na realidade, de um processo dialético, no qual a prática vai dar sentido à teoria e a teoria, por sua vez, irá retroagir e contribuir para ressignificar a prática profissional, o que remete à necessidade de instaurar uma práxis que, historicamente, vem sendo perdida nos cursos da área de saúde (Santos, \& Hormanez, 2013). "Aconteceu de, na prática, na hora dos vamos ver, nos momentos complicados, eu me recordar do que foi ensinado no curso e isso me ajudou muito. Acredito que esse apoio deveria ser dado para todos" (Participante 1).

Esse acompanhamento teórico e prático, em especial para profissionais em formação, é bastante valorizado pelo graduando, que muitas vezes se percebe solitário e sem apoio na prática em saúde, tentando equilibrar suas angústias e inseguranças com as obrigações, expectativas e cobranças (externas e autoimpostas), ou que nele são maciçamente depositadas (Bernieri, \& Hirdes, 2007). "Poder compartilhar com as outras pessoas o que estava passando, e não me sentir sozinha, fez toda a diferença" (Participante 7).

Aceitar a morte como um fenômeno natural, deslocando-a do espaço do inaceitável, é uma dimensão que aparece no relato da maioria das participantes, sendo reconhecida como um elemento fundamental e transformador da prática clínica. A morte parece passar da posição de escamoteada para visível, de interdita para pensável, de silenciada para conversável, o que gera repercussões no paciente, no familiar e no cuidador (Macedo, Macedo, \& Gomes, 2010). Uma vez que não seja mais negada, a condição de terminalidade pode ser pensada e estratégias de ajuda mais efetivas podem ser implementadas. "Sinto que consigo aceitar melhor a morte como fazendo parte da vida. Isso com certeza me ajudou a lidar melhor com pacientes em estado crítico" (Participante 8).

A mudança de atitude frente à morte reflete-se também em alterações percebidas nos sentimentos e sensações relatadas após a intervenção, que passaram a ser de: alívio, capacidade, tranquilidade, maturidade, aceitação, confiança, sensibilidade, esclarecimento, parceria e solidariedade: "Sinto-me mais capacitada a lidar melhor com pacientes em estado crítico, e a apoiá-los e passar as informações no momento certo" (Participante 6).

As participantes demonstraram ter compreendido que se trata de um processo de aprendizagem sobre a morte e o morrer que teve apenas o seu início no Grupo, e que não se esgota nele, pois irá prosseguir doravante na experiência de cada um rumo à construção de seu futuro profissional. Evidenciaram também que estão adquirindo uma percepção diferenciada sobre a morte. "Não me sinto preparada para lidar com qualquer situação, mas sinto que o processo da morte se tornou mais natural" (Participante 4).

O processo educativo, apesar de ser uma intervenção modesta e limitada no tempo, gerou possibilidades de mudanças que, eventualmente, podem ser mais duradoras, uma vez que exerceu a função de instrumentalizar as participantes:

O trabalho proporcionou ferramentas paralidarmos comas angústias decorrentes do sofrimento/doença com que muitas vezes nos deparamos na prática clínica. Foi bom ter um espaço para compartilhar experiências e adquirir conhecimento técnico de como lidar com algumas situações me trouxeram não só conforto, mas segurança no desenvolvimento de minhas atividades (Participante 2).

\section{Considerações Finais}

Este estudo reportou a configuração e implementação de uma intervenção educativa denominada Grupo de Educação para a Morte, que seguiu as orien- 
tações preconizadas pela literatura (Kovács, 2005). O conhecimento produzido delimita uma estratégia com base em um modelo de curta duração, alicerçado em teoria e reflexões psicológicas sobre a terminalidade. Procurou-se favorecer o contato das participantes com os próprios sentimentos e com o mundo interno das demais colegas, trabalhando-se temas relacionados à comunicação com o paciente, familiar e equipe de saúde, e ao manejo de situações críticas da prática em saúde (Kovács, 2009).

Pode-se afirmar que, na perspectiva das participantes, o trabalho do Grupo de Educação para a Morte cumpriu satisfatoriamente seu propósito, possibilitando reflexões sobre a morte e o morrer no hospital, por meio de uma aprendizagem significativa, que envolveu a integração dos aspectos cognitivos e afetivos, e que levou em consideração a experiência de prática clínica das alunas. Os resultados corroboram achados de outros estudos, que mostram a importância do ensino de abordagens e condutas frente à terminalidade (Marta et al., 2015; Sullivan et al., 2005; Ury et al., 2002), de maneira a conferir visibilidade às questões relacionadas à finitude humana.

Na trajetória dos encontros grupais foi observada a possibilidade de reconsideração (ou até mesmo de ressignificação, em alguns casos) da morte e do luto, como recomendado por Kovács (2009), de modo individual e coletivo, possibilitando uma revisão das práticas. Esses benefícios do Grupo parecem ser incrementados quando se considera e se valoriza a participação ativa do aluno na construção desse conhecimento.

É importante ressaltar que não se trata de um trabalho fácil e muito menos que se encerra quando a intervenção termina, uma vez que seu intuito é o de potencializar reflexões ininterruptamente e desencadear questionamentos sobre um tema ainda obscuro e pouco explorado. Também deve ser pontuado que, para que essa empreitada alcance êxito, é de fundamental importância que os participantes estejam motivados e autenticamente disponíveis para a tarefa grupal, uma vez que serão expostos a temas sensíveis e tocados em experiências sofridas de seu ser (Kovács, 2005). Nesse contexto, trata-se de um trabalho que tem início, mas que não se esgota em sua delimitação operacional, uma vez que é processual. É um tipo de intervenção cujos desdobramentos precisam ser continuamente refletidos na prática clínica.

Na sociedade ocidental contemporânea a morte ainda continua interdita e oculta nos ambientes hospitalares. Paradoxalmente, o tema da educação para a morte vem sendo valorizado de forma crescente, tornando-se cada vez mais alvo de estudos e interesse científico. O que se observa no exercício cotidiano são as chamadas zonas de silenciamento, que se configuram como lacunas na comunicação profissional-paciente, profissional-família e entre os próprios profissionais, sendo que o agravamento clínico e a eventual morte do paciente ainda tendem a ser encarados como evidência de fracasso pessoal do trabalhador da saúde, incrementando vivências depressivas e sentimentos de impotência (Penello, \& Magalhães, 2010).

Consequentemente, reforça-se a necessidade de ampliação e divulgação de estudos dessa natureza, tendo em vista "a urgência na introdução de uma visão crítico-reflexiva para o processo de morte e morrer na formação acadêmica" (Santos, \& Bueno, 2011, p. 275). Uma sugestão para enfrentar esse problema é investir na expansão do trabalho educativo junto a docentes e supervisores da área da saúde e educação, assim como dialogar para além do meio profissional e acadêmico, para que se possam alcançar outros setores da vida comunitária.

\section{Referências}

Aoki, F., Oliveira-Cardoso, E. A., \& Santos, M. A. (2013). Significado da morte para médicos frente à situação de terminalidade de pacientes submetidos ao Transplante de Medula Óssea. Ciência \& Saúde Coletiva, 18(1), 2625-2634. https://doi.org/10.1590/S1413-81232013000900017

Arruda-Colli, M. N. F., Perina, E. M., Mendonça, R. M. H., \& Santos, M. A. (2015). Intervenção psicológica com familiares enlutados em oncologia pediátrica: revisão da literatura. Psicologia: Teoria e Prática, 17(2), 20-35. http://dx.doi.org/10.15348/1980-6906/psicologia.v17n2p20-35

Arruda-Colli, M. N. F., \& Santos, M. A. (2015). Aspectos psicológicos da recidiva em Oncologia Pediátrica: uma revisão integrativa. Arquivos Brasileiros de Psicologia, 67(3), 75-93.

Arruda-Colli, M. N.F., Perina, E. M., \&Santos, M.A. (2015). Experiences of Brazilian children and family caregivers facing the recurrence of cancer. European Journal of Oncology Nursing, 19(5), 458-464. doi: 10.1016/j.ejon.2015.02.004 
Azeredo, N. S. G., Rocha, C. F., \& Carvalho, P. R. A. (2011). O enfrentamento da morte e do morrer na formação de acadêmicos de Medicina. Revista Brasileira de Educação Médica, 35(1), 37-43. https:// doi.org/10.1590/S0100-55022011000100006

Bernieri, J., \& Hirdes, A. (2007). O preparo dos acadêmicos de enfermagem brasileiros para vivenciarem o processo de morte-morrer. Texto \& Contexto Enfermagem, 16(1), 89-96. https:// doi.org/10.1590/S0104-07072007000100011

Bleger, J. (2003). Psico-higiene e psicologia institucional (E. O. Diehl, trad.). Porto Alegre, RS: Artmed.

Brabant, S., \& Kalish, D. A. (2008-2009). Who enrolls in college death education courses? a longitudinal study. Omega (Westport), 58(1), 1-18.

Brasil. (2012, 13 de dezembro). Ministério da Saúde. Conselho Nacional de Saúde. Resolução No 466 , de 12 de dezembro de 2012. Aprovar diretrizes e normas regulamentadoras de pesquisas envolvendo seres humanos. Diário Oficial da União.

Brasil. (2009). Ministério da Saúde. Secretaria de Atenção à Saúde. Humaniza SUS: redes de produção de saúde. Brasília, DF: o autor.

Cardoso, E. A. O., \& Santos, M. A. (2013). Luto antecipatório em pacientes com indicação para o transplante de células-tronco hematopoéticas. Ciência \& Saúde Coletiva, 18(1), 2567-2575. https:// doi.org/10.1590/S1413-81232013000900011

Castro, D. A. (2001). Psicologia e ética em cuidados paliativos. Psicologia: Ciência e Profissão, $21(4), 44-51$. https:// doi.org/10.1590/S1414-98932001000400006

Cesnik, V. M., Vieira, E. M. V., Giami, A., Almeida, A. M., Santos, D. B., Santos, M. A. (2013). The sexual life of women with breast cancer: meanings attributed to the diagnosis and its impact on sexuality. Estudos de Psicologia (Campinas), 30(2), 187-197. http://dx.doi.org/10.1590/S0103-166X2013000200005

Fish, S. \& Shelly, J. A. (1986). Cuidado espiritual do paciente. São Paulo, SP: Umhe.

Junqueira, M. H. R., \& Kovács, M. J. (2008). Alunos de Psicologia e a educação para a morte. Psicologia: Ciência e Profissão, 28(3), 509-519. https://doi.org/10.1590/S1414-98932008000300006

Kovács, M. J. (2005). Educação para a morte. Psicologia: Ciência e Profissão, 25(3), 484-497. https:// doi.org/10.1590/S1414-98932005000300012

Kovács, M. J. (2009). Educação para a morte. In F. S. Santos (Org.), Cuidados paliativos: discutindo a vida, a morte e o morrer (pp. 45-59). São Paulo, SP: Atheneu.

Kovács, M. J. (2003). Os profissionais de saúde e educação e a morte. In M. J. Kovács (Org.), Educação para a morte: desafio na formação de profissionais de saúde e educação (pp. 23-70). São Paulo, SP: Casa do Psicólogo.

Macedo, F. D. C., Macedo, J. C. G., \& Gomes, M. F. P. (2010). Educar para a morte e a promoção da saúde mental. Revista Portuguesa de Enfermagem de Saúde Mental, 3(1), 48-53.

Marta, G. N., Marta, S. N., \& Job, J. R. P. P. (2009). O estudante de Medicina e o médico recém-formado frente à morte e ao morrer. Revista Brasileira de Educação Médica, 33(3), 405-416. https://doi.org/10.1590/S0100-55022009000300011

Menezes, C. N. B., Passareli, P. M., Drude, F. S., Santos, M. A., \& Valle, E. R. M. (2007). Câncer infantil: organização familiar e doença. Revista Mal-Estar e Subjetividade,7(1), 191-210.

Oliveira, E. A., Santos, M. A., \& Mastropietro, A. P. (2010). Apoio psicológico na terminalidade: ensinamentos para a vida. Psicologia em Estudo, 15(2), 235-244. https://doi.org/10.1590/S1413-73722010000200002

Penello, L., \& Magalhães, P. (2010). Comunicação de más notícias: Uma questão se apresenta. In Instituto Nacional de Câncer. Coordenação Geral de Gestão Assistencial. Coordenação de Educação. Comunicação de notícias difíceis: compartilhando desafios na atenção à saúde (pp. 23-26). Rio de Janeiro, RJ: INCA.

Pereira, T. T. S. O., \& Santos, M. A. (2012). Care group for mental health staff: a professional development strategy. Revista Brasileira de Crescimento e Desenvolvimento Humano, 22(1), 68-72.

Pessini, L., \& Barchifontane, C. P. (2002). Progresso tecnocientífico, medicina e humanização. In L. Pessini \& C. P. Barchifontane (Orgs.), Problemas atuais de Bioética (6a ed., pp. 117-136). São Paulo, SP: Loyola. 
Pregnolatto, A. N. F., Agostinho, V. B. M., Dias, R. R., \& Baptista, M. N. (2003). Humanização em ambientes médicos. In M. N. Baptista, \& R. R. Dias (Orgs.), Psicologia Hospitalar: teoria, aplicações e casos clínicos (2a ed., pp. 157-170). Rio de Janeiro, RJ: Guanabara Koogan.

Quintana, A. M., Kegler, P., Santos, M. S., \& Lima, L. D. (2006). Sentimentos e percepções da equipe de saúde frente ao paciente terminal. Paidéia (Ribeirão Preto), 16(35), 415-425. https://doi.org/10.1590/S0103-863X2006000300012

Quintana, A. M., Rodrigues, A. T., Arpini, D. M., Bassi, L. A., Cecim, O. S., \& Santos, M. S. (2008). A angústia na formação do estudante de medicina. Revista Brasileira de Educação Médica, 32(1), 7-14. https://doi.org/10.1590/S0100-55022008000100002

Santos, D. B., Ford, N. J., Santos, M. A., \& Vieira, E. M. (2014). Breast cancer and sexuality: the impacts of breast cancer treatment on the sex lives of women in Brazil. Culture, Health \& Sexuality, 16(3), 246-257. http://dx.doi.org/10.1080/13691058.2013.867075

Santos, J. L., \& Bueno, S. M. V. (2011). Educação para a morte e docentes e discentes da enfermagem: revisão documental da literatura cientifica. Revista Escola de Enfermagem da USP, 45(1), 272-276. https://doi.org/10.1590/S0080-62342011000100038

Santos, M. A. (2003). Perto da dor do outro, cortejando a própria insanidade: O profissional de saúde e a morte. Revista da SPAGESP, 4(4), 43-51.

Santos, M. A., \& Hormanez. M. (2013). Atitude frente à morte em profissionais e estudantes de enfermagem: revisão da produção científica da última década. Ciência \& Saúde Coletiva. 18(1), 2757-2768. https://doi.org/10.1590/S1413-81232013000900031

Souza, B. F., Moraes, J. A. M., Inocenti, A., Santos, M. A., Silva, A. E. B. C., \& Miasso, A. I. (2014). Women with breast cancer taking chemotherapy: depression symptoms and treatment adherence. Revista Latino-Americana de Enfermagem, 22(5), 866-873. http://dx.doi.org/10.1590/0104-1169.3564.2491

Sullivan, A. M., Lakoma, M. D., Billings, J. A., Peters, A. S., \& Block, S. D. (2005). Teaching and learning end-of-life care: evaluation of a faculty development program in palliative care. Academic Medicine, 80(7), 657-668.

Toledano, E., \& Narache, O. (Diretores). (2012). Intocáveis (Filme-vídeo). França. California Filmes.

Triviños, A. N. S. (1992). Introdução à pesquisa em ciências sociais: a pesquisa qualitativa em educação. São Paulo: Atlas.

Tucker, T. (2009). Culture of death denial: relevant or rhetoric in medical education? Journal of Palliative Medicine, 12(2), 1105-1108. https://doi.org/10.1089/jpm.2009.0234

Ury, W. A., Arnold, R. M., \& Tulsky, J. A. (2002). Palliative care curriculum development: a model for a content and process-based approach. Journal of Palliative Medicine, 5(4), 539-548. https://doi.org/10.1089/109662102760269779

Vieira, E. M., Ford, N. J., Santos, M. A., Junqueira, L. C. U., \& Giami, A. (2013). Representations of nurses regardind sexuality of women treated for breast cancer in Brazil. Cadernos de Saúde Pública, 29(10), 2049-2056. http://dx.doi.org/10.1590/0102-311X00158512

\section{Érika Arantes Oliveira-Cardoso}

Psicóloga do Departamento de Psicologia da Faculdade de Filosofia, Ciências e Letras de Ribeirão Preto, Universidade de São Paulo, Ribeirão Preto, SP, Brasil. Membro do Laboratório de Ensino e Pesquisa em Psicologia da Saúde (LEPPS-USP-CNPq).

E-mail: erikaao@ffclrp.usp.br

\section{Manoel Antônio dos Santos}

Professor Associado 3 do Departamento de Psicologia da Faculdade de Filosofia, Ciências e Letras de Ribeirão Preto, Universidade de São Paulo, SP, Brasil. Bolsista de Produtividade em Pesquisa do CNPq, nível 1B. Coordenador do Laboratório de Ensino e Pesquisa em Psicologia da Saúde (LEPPS-USP-CNPq).

E-mail: masantos@ffclrp.usp.br 
Endereço para envio de correspondência:

Universidade de São Paulo, Departamento de Psicologia da Faculdade de Filosofia, Ciências e Letras de Ribeirão Preto, SP, Brasil. Laboratório de Ensino e Pesquisa em Psicologia da Saúde - LEPPS (FFCLRP-USP-CNPq). Avenida Bandeirantes, 3900, Monte Alegre. CEP: 14040-901. Ribeirão Preto - SP, Brasil

Recebido 01/09/2015

Reformulação 12/04/2016

Aprovado 10/02/2017

Received 09/01/2015

Reformulated $04 / 12 / 2016$

Approved 02/10/2017

Recebido 01/09/2015

Reformulado 12/04/2016

Aceptado 10/02/2017

Como citar: Oliveira-Cardoso, E. A., \& Santos, M. A. (2017). Grupo de Educação para a Morte: uma estratégia complementar à formação acadêmica do profissional de saúde. Psicologia: Ciência e Profissão, 37(2), 500-514. http://doi.org/10.1590/1982-370302792015

How to cite: Oliveira-Cardoso, E. A., \& Santos, M. A. (2017). Death education group: a strategy to complement undergraduate education of health professionals. Psicologia: Ciência e Profissão, 37(2), 500-514. http://doi.org/10.1590/1982-370302792015

Como citar: Oliveira-Cardoso, E. A., \& Santos, M. A. (2017). Grupo de educación para la muerte: una estrategia complementaria a la formación de pregrado del profesional de la salud. Psicologia:Ciênciae Profissão, 37(2), 500-514. http://doi.org/10.1590/1982-370302792015 